\title{
Heterotopic gastric mucosa of the ileum
}

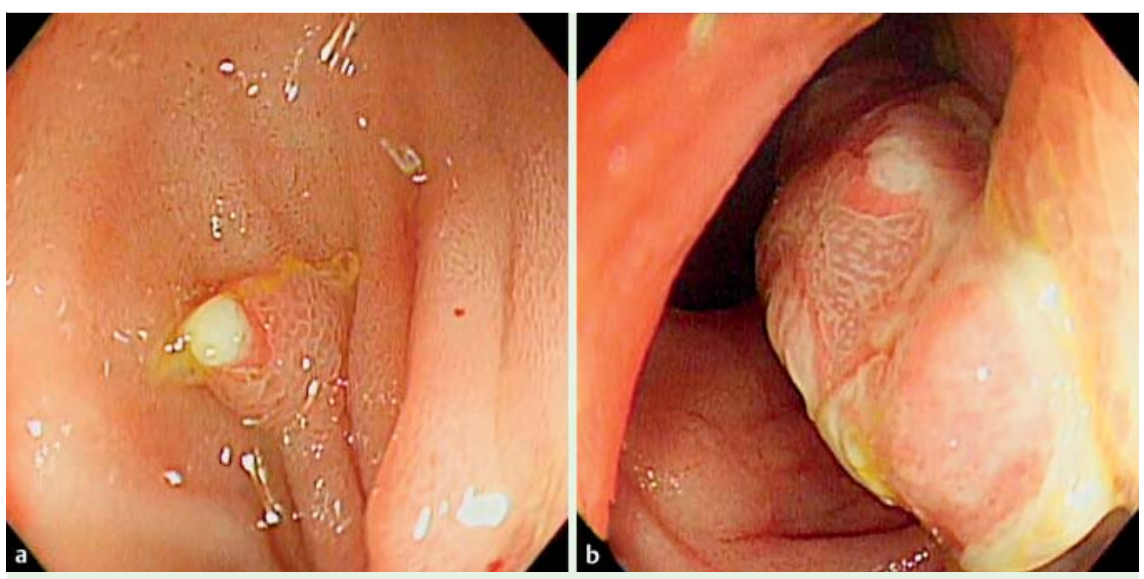

Fig. 1 Colonoscopic views of the terminal ileum showing several polypoid lesions, measuring $0.3-0.8 \mathrm{~cm}$, with surface ulceration.
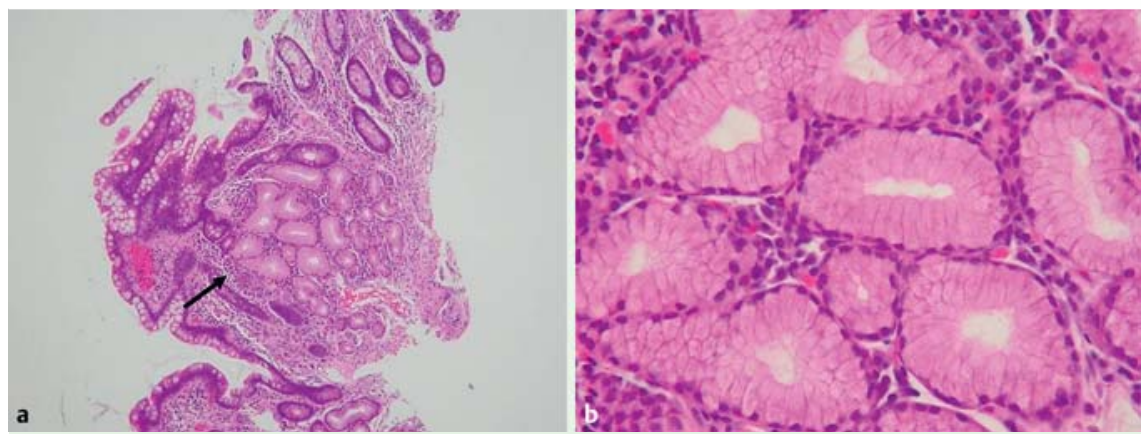

Fig. 2 Hematoxylin and eosin (H\&E)-stained images of the biopsy specimens taken from the polypoid lesions showing: a mucinous glands in the lamina propria (arrow), which resemble the pyloric glands of the stomach (original magnification $\times 100$ ); $\mathbf{b}$ higher power view of the mucinous glands (original magnification $\times 400)$.

A 70-year-old woman with a history of breast cancer underwent colonoscopy because of a positive fecal blood test. Her physical examination was unremarkable, but her hemoglobin level was $9.9 \mathrm{~g} / \mathrm{dL}$ (normal range $13.5-17.5 \mathrm{~g} / \mathrm{dL}$ ). The colonoscope reached to $8 \mathrm{~cm}$ above the ileocecal valve. In addition to internal and external hemorrhoids, several polypoid lesions measuring $0.3-0.8 \mathrm{~cm}$, with surface ulceration, were found in the terminal ileum ( Fig.1). Histopathological examination of the biopsy specimens taken from these polypoid lesions revealed mucinous glands in the lamina propria that resembled the pyloric glands of the stomach ( Fig.2). A diagnosis of heterotopic gastric mucosa (HGM) of the ileum was made on the basis of the histological findings. Because of the patient's poor overall condition and the fact that she had no major complications from the HGM, further observation alone was recommended.

Although HGM may occur throughout the alimentary tract, especially in the proximal esophagus, duodenum, and in a Meckel's diverticulum, it is rarely found in the jejunum and ileum; most cases of jejunal and ileal HGM are diagnosed on the basis of histological results from surgical specimens [1]. HGM usually appears as an "inlet patch" in the upper third of the esophagus, as nodular masses in the duodenum, or as polypoid masses in other parts of the small intestine [2,3].

HGM may be congenital or acquired, but the mechanism remains unknown. Acquired HGM represents replacement of the native mucosa by gastric epithelium because of various inflammatory or peptic processes [1].

HGM is usually clinically silent and does not require treatment; however, surgical intervention can be considered in patients with complications such as bleeding or intestinal obstruction [1]. Therefore, although HGM of the ileum is extremely rare, it should be considered in the differential diagnosis of ileal polypoid lesions.

Endoscopy_UCTN_Code_CCL_1AC_2AF

Competing interests: None

\section{Chi-Ming Tai', I-Wei Chang², Hsiu-Po Wang ${ }^{3}$}

${ }^{1}$ Department of Internal Medicine Pathology, E-Da Hospital, I-Shou University, Kaohsiung, Taiwan

2 Department of Pathology, E-Da Hospital, I-Shou University, Kaohsiung, Taiwan

${ }^{3}$ Department of Internal Medicine, National Taiwan University Hospital, National Taiwan University, Taipei, Taiwan

\section{References}

1 Boybeyi O, Karnak I, Güçer $S$ et al. Common characteristics of jejunal heterotopic gastric tissue in children: a case report with review of the literature. J Pediatr Surg 2008; 43: e19-e22

2 Yu L, Yang Y, Cui L et al. Heterotopic gastric mucosa of the gastrointestinal tract: prevalence, histological features, and clinical characteristics. Scand J Gastroenterol 2014; 49: $138-144$

3 Hammers YA, Kelly DR, Muensterer OJ et al. Giant polypoid gastric heterotopia with ectopic thyroid tissue: unusual cause of jejuno-jejunal intussusception. J Pediatr Gastroenterol Nutr 2007; 45: 484-487

\section{Bibliography}

Dol http://dx.doi.org/

10.1055/s-0034-1392666

Endoscopy 2015; 47: E423

(c) Georg Thieme Verlag KG

Stuttgart · New York

ISSN 0013-726X

\section{Corresponding author}

\section{Hsiu-Po Wang, MD}

Department of Internal Medicine

National Taiwan University Hospital

No.7, Chung-Shan South Road

Taipei

Taiwan, ROC

Fax: +886-2-23947899

wanghp@ntu.edu.tw 